\title{
Lost in translation: tracing the erasure of the critical dimension of a radical educational discourse.
}

\begin{abstract}
This paper demonstrates that the presence of radical discourse in an educational field is not necessarily evidence of criticality in practice. Appropriated by policy and practitioners within a web of power relations, the discourse may come to act on practice in ways which are antithetical to its theoretical origins. To illustrate this process of transformation and its effects, the paper explores the work of the discourse of the Scottish 'social practice approach' as an actant in the Scottish Adult Literacy and Numeracy (ALN) initiative 2000-2012. The argument uses ideas from Actor-Network theories, in particular the concept of 'translation', to make sense of the apparent contradictions in the Scottish context. Seemingly derived from the New Literacy Studies (NLS), the concept of 'the social practice approach' implies a critical pedagogy. Its prominence in the discourses of ALN in Scotland might indicate critical practice. Despite Scottish practitioners' claims to 'do social practices' there is, however, little evidence of such practice. Part of a larger study of the Scottish ALN reforms, this examination of the emergence and stabilisation of the 'social practice' discourse suggests that in translations the associations with NLS were betrayed through relationships with other powerful discourses. Ironically, the effect of the discourse of 'the social practice approach' may have been to contribute to the effective mobilization of Scottish practitioners to the role assigned to them in the government human capital project and to obviate resistance. The paper concludes with some thoughts about the potential for intervention to open up spaces in which alternative constructions of literacy and literacy education can be assembled.
\end{abstract}

Key terms: Adult Literacies; New Literacies Studies; Actor-Network theories.

\section{Introduction}

This paper arises out of research into the Scottish ALN initiative (2000-2012) and what is referred to as the Scottish 'social practice approach' to literacies education. I began with an analysis of the hybrid discourses in policy (Ackland, 2006), arguing that the radical adult learning discourses are recontextualised by a powerful performativity discourse linked to economic drivers. I explored the relationship between theory and practice through an enquiry into how practitioners understand 'a social practice approach' (Ackland, 2010). Differences between theoretical understandings of literacies as social practices and how practitioners construe 'a social practice approach' led me to an examination of the shifts in the discourse as it travelled from the knowledge production field to the field of practice through what Bernstein (1981) refers to as the recontextualising field (Ackland, 2013). In this work my interest was in the relationship between the meanings of theories of social practices and the meanings of 'the social practice approach' as represented in Scottish policy and practice. My conclusion - that the Scottish 'social practice approach' is not consistent with the implications of social practices theories of literacies - led me to new questions. What is the power of 'the social practice approach' in Scotland? Why has this discourse taken such hold in Scotland, how is it embroiled in power relations and what effects does it have? In this paper, then, my starting point is different. No longer concerned with whether or not 'the social practice approach' is related to the theory of social practices, I begin with the premise that it - 'the social practice approach' - is an entity in its own right. I am moving on from a concern with what the discourse means to a consideration of what work the discourse is doing (Usher and Edwards, 2007, p.156). 
To explore this, I have turned to Actor-Network theories (ANT) which see 'everything in the social world as a continuously generated effect of the web of relations within which they are located' (Law, 2007, in Fenwick and Edwards, 2010, p.2). Accordingly, 'the social practice approach' is not a direct derivation of social practices theory. Instead it can be viewed as an actor-network, an effect of a web of relations (a network) and an actor (or actant) which has effects on the web of relations in which it is located.

My broad concern is with the appropriation of radical educational discourses which constrains and controls practice. ANT encourages me to trace the complexity of this process in a specific situation. The local detail, the particularity, is necessary to try to show what is contingent, ambivalent, messy. The argument about the threat of global hegemony to local practice has significance, however, beyond any particular national context.

After an introduction to the Scottish context and to ANT, the paper explores the alliances out of which the term 'the social practice approach' was generated. It traces how the discourse circulates among actors who form alliances in the webs of relations that make up the field of ALN policy and practice in Scotland. The paper considers what work the discourse may be doing within a set of power relations that constitute such webs. Finally some consideration is given to the potential for making use of these insights to intervene and open up space for alternative conceptions of Adult Literacies work.

\section{Setting the scene: The Scottish ALN context - a contradictory and confusing space}

ALN became a policy priority in Scotland in the decade from 2000, as in many countries worldwide. National strategy in 2001 was informed by the Organisation for Economic Cooperation and Development (OECD) International Adult Literacy Survey (IALS); the expressed goal to 'exceed world class levels of literacy and numeracy' (Scottish Executive, 2001, p.1) reflects the OECD conclusion that 'strategies to build literacy skills are pivotal for developing competitive advantage’ (OECD website).

The Scottish strategy texts contain an assortment of conflicting discourses (Ackland, 2006; Maclachlan, 2006). The economic imperative belies the wider social justice rhetoric 'which sees literacies as a key dimension of community regeneration and the wider lifelong learning agenda' (Communities Scotland website, 2005). A deficit perspective of learners as having expressed, latent or invisible need for functional skills (Scottish Executive, 2001, p.15) is inconsistent with the breadth of the socio-cultural definition of literacies: 'The ability to read, write and use numeracy, to handle information, to express ideas and opinions, to make decisions and solve problems, as family members, workers, citizens and lifelong learners' (ibid, p.7).

The strategic guidance (Scottish Executive, 2001) addressed a diverse field of practice in which practice cultures in community based adult learning, further education and the voluntary sector arise from conflicting ideologies (Ackland, 2010; Crowther and Martin, 2010). Given these differences, it is surprising that one discourse has become pervasive, linking policy and practice and giving the impression of national coherence and consistency.

The discourse of 'the social practice approach' circulates in practice-facing texts (most notably, An Adult Literacy and Numeracy Curriculum framework for Scotland, Scottish Executive, 2005), practice reports, in practitioner networks and in spaces of practice 
deliberation such as professional development programmes. Practitioners invariably describe themselves as 'doing the social practice approach' (Jones and Macrae, 2008; Ackland, 2010; Swinney, 2013). Swinney (2013) describes the discourse as 'authorised' (p.242), an 'orthodoxy' (p.244), 'hegemony' (p.35) and a 'regime of truth' (p.245).

The term the 'social practice approach' invokes the social practice perspective of literacies theorised by the NLS (see for example, Street, 1984); implications of this perspective for literacies education are that, 'A critical pedagogy is required which takes account of the power relationships affecting use of literacies in everyday life' (Hillier, 2008, p.6).

Despite the prevalence of the discourse of 'the social practice approach', little evidence is found of such pedagogy in Scottish practice (Maclachlan, 2006; Hillier, 2008; Tett \& Maclachlan, 2008; Ackland, 2013; Swinney, 2013). Swinney (2013, p.237) concludes that 'the uniformity of literacy practitioners' discourses masked underlying differences'. Contradictory values, assumptions and pedagogical approaches were also identified in my own study of practitioners' constructs of practice (Ackland, 2013). Nevertheless, practitioners in that study saw themselves as conforming to 'the social practice approach'.

The recent update of the Scottish strategy claims that 'over 200,000 adults have improved their reading, writing and number skills' (Scottish Government, 2010, p.7). It asserts that these are "most successfully taught using a "social practice" approach. This model of delivery emphasises the importance of a learner-centred approach and personal curriculum' (ibid). The connection made here between the 'social practice' approach and a 'learner-centred', 'personal curriculum', is incongruous. As Tett and Maclachlan (2008, p.670) point out, the critical pedagogy that flows from a social practice perspective of literacies, 'is a collective process, whereby people ....question together the asymmetrical power relationships that have marginalised them and their practices'. In the claim made in the Government text, the social ordering of literacy as a set of autonomous skills residing in the minds of individuals to be developed for more effective socio-economic participation is not threatened. The critical dimension of the social practices perspective of literacies as inherently ideological is erased. The updated strategy links literacy to economic productiveness even more overtly.

The Scottish context is thus confusing. The discourse of 'a social practice approach' is shared by practitioners and policy makers. Such consistency in a field of practice characterised by ideological differences is itself remarkable. More puzzling still is the variety of interpretations of 'a social practice approach' which survive unchallenged despite a culture of conformity (Swinney, 2013). This paper does not concern itself, however, with the meanings of 'a social practice approach'. This paper aims to build on my previous research to explore 'the social practice approach' as an actant doing work within a web of relations.

\section{Actor-Network Theories}

ANT is promoted as an approach to educational research which can help us draw closer to an apprehension of the complexity of the problems of educational policy and practice. Fenwick and Edwards (2010) argue for a use of ANT that resists the reductionism of the application of a unified totalising theory. They encourage the cultivation of a 'sensibility', utilising ANT as 'an array of practices for approaching complexity in the world and its problems':

'ANT approaches can enact questions and phenomena in rich ways that discern difficult ambivalences, messy objects, multiple overlapping worlds and apparent 
contradictions that are embedded in many educational issues' (Fenwick and Edwards, 2010, p.ix)

As a 'diaspora' (Law, 1999, p.10) of theoretical conceptions, ANT has been elaborated in a wide range of domains, including marine biology (Callon, 1986), public health (Singleton and Michael, 1993) and computer technology (Nespor, 2011). Many studies focus on change initiatives and seek to understand how such initiatives become enacted over time and across various contexts. In educational research, ANT approaches are proving particularly useful for exploration of policy reforms (e.g. Fenwick, 2011; Hamilton, 2001; Clarke, 2002). These studies share a sensibility towards the circulation of power within a field of practice at moments of change. The relations attended to are not only those between human actors; they include the relations between human and non human actors. Perhaps the most radical tenet of ANT is that non -human as well as human entities have the potential to exert agency and participate in the ordering of social relations. They must therefore be treated as equivalent in any analysis. In Actor-Network theories the hyphen signifies the correlation between actors and networks in which actors are not discrete separate entities but are themselves the effect of a network. Networks are the effect of assemblages of entities, or actors. ANT is sometimes referred to as a sociology of translation. The term 'translation' is used to describe what happens when entities (human and non-human) are connected, forming links in which the entities are each changed (Fenwick and Edwards, 2010, p.9). Most significant for my analysis is Law's definition of translation as 'the process or the work of making two things that are not the same, equivalent' (Law, 1999, p.8).

Bringing ANT to the study of educational reform in ALN, Clarke proposes a view of '...policy and practice as effects of power circulating in networks of human and non-human entities' (Clarke, 2002, p.107). Her analysis of the English Skills for Life initiative uses the framework of Callon's (1986) four moments of translation to explore how diverse actors are enrolled into the problematization of adult skills deficits and mobilised to a human capital project for economic growth. This is one of a growing number of ANT analyses of recent reforms in the English ALN field which explore the powerful effects between policy and practice in a diffuse, heterogeneous and value-laden field. Hamilton (2010) argues that ANT sensibilities are particularly appropriate for the study of the policy and practice of literacy given that recent theoretical conceptions emphasise the contingency of ideological social constructions of what constitutes literacy and the dynamic multiplicity of the social practices of literacies (for an introduction to this perspective see Crowther et al, 2001). Moreover, 'Adult Literacy education is such a loosely framed field of social action and needs an analytic approach that can deal with issues of power and conflict' (Hamilton, 2010, p.4).

Clarke (2002), Hamilton $(2001,2009,2010)$ and Burgess $(2008,2012)$ then, have fruitfully brought ANT sensibilities to explorations of changing policies and practice of ALN in England in the period 2000-2012. They draw attention to the ways in which assemblages of global and local networks effect translations in which educational practice is potentially locked down in particular framings of literacy and literacy education. Much of their analyses can be mapped on to the Scottish situation in a similar period. The global networks they identify such as the OECD, IALS, international agencies, European Basic Skills policy are as relevant in Scotland and, although minor differences in the history and conditions of practice may be traced, their descriptions of the ALN field as plural, contested and loosely bound hold good for Scotland (see Crowther and Martin, 2010). Despite this, the ALN initiative in Scotland in the last decade has been differentiated by a single powerful discourse which has not been evident elsewhere. 'The social practice approach' has attracted envious attention 
from England (Merrifield, 2005); it has been seen as characterising a distinctive framing of literacy and literacy education in which the power relations between government, practitioners and learners do not replicate the hierarchical relationships elsewhere in the UK. The discourse of 'the social practice approach' may be considered an actor-network in the reforms in Scotland, which is not evident in the analyses of the English initiative. It might be expected that its presence within the assemblages of actor-networks in Adult Literacy reform would have the effect of maintaining more open spaces for practitioners and learners, permitting wider conceptions of literacy and literacy education to escape the stranglehold of the human capital project. In this paper I will build on the ANT analyses of the English initiatives to suggest that the opposite may be the case; that instead, the translations in the Scottish initiative may have 'betrayed' the constructions of literacy and literacy education of the New Literacy Studies and delivered practitioners and learners more surely into the mobilization of government's economic project.

\section{My position and method}

Ideas drawn from ANT are compatible with ethnographic approaches which draw on data from different times and contexts to explore the co-relationships of macro and micro processes. ANT's conception of the world as messy, uncertain and constantly in flux implies a method of data gathering that does not pretend to be objective, systematic and comprehensive. Rather it is varied, multi-perspectival and inherently embedded. The data I draw on for this paper has been gathered over a period of 10 years in which I have been a practitioner, teacher educator and researcher in Adult Literacies in Scotland. At times I have also been involved in processes of policy consultation and formulation. I make no claim to neutrality; I am enmeshed in the network of relations which I strive to understand.

As well as amassing a collection of artefacts from the ALN initiative, I have undertaken two linked research projects in this period - a critical discourse analysis of policy (Ackland, 2006) and a study of practitioners' ways of construing (Ackland, 2013) both of which involved dialogues with teachers, managers and policy actors from across Scotland. The initial study (2004 -2006) used techniques of Critical Discourse Analysis (Fairclough, 2003) to examine the language of key policy documents and a range of written and oral material generated by stakeholders in the initiative (e.g. local literacies partnerships plans and reports). To capture how people were discussing change informally I undertook dialogues with six people working at different levels within the adult literacies field in Scotland. Transcriptions of the dialogues created additional 'text' for discourse analysis. In the second study (20082010), practitioners studying for a teaching qualification engaged in a variety of processes to elicit implicit theories of practice, including dialogues which used the structured Repertory Grid technique (Fransella and Bannister, 1977). Practitioner quotes used later in the paper are taken from these two studies and were collected ethically as part of the research.

As a teacher educator with a lead role in the collaborative delivery of a national professional development programme for ALN teachers in Scotland, I am in communication with colleagues at all levels of practice and have opportunities to observe practice in a range of contexts. My data include my own reflective 'field notes'. It is worth noting in this that Scotland is a small country and the ALN field a very small part of it. My roles, firstly as a regional practice manager and then as a teacher educator involved in professional development nationally, afforded me relationships which are geographically spread, crosssectoral and multi-level. This is not to claim a comprehensive view, rather to acknowledge my complicity. 
My data and the analyses have been cumulative. As stated in the introduction, my research focus evolved. Enquiring into ongoing processes of change, I have found myself revisiting the accumulating data with different theoretical lenses selected for their relevance to emergent questions. This analysis revisits the data with an ANT sensitivity to address the specific question of how one discourse has acted over time in the change process. Drawn to ANT by Fenwick and Edwards' promotion of it as 'a way to intervene' (2010, pp.1-23), I share with Clarke (2002), Hamilton (2010) and Burgess (2012), the motivation to find spaces in which alternative constructions of literacy and literacy education can be assembled.

The organisation and interpretation of the material is guided by a number of key concepts from ANT, which provide a way into examining significant points of dense connection in the trajectory of a network. Callon's (1986) model of four moments of translation through which networks are formed (problematization, interessement, enrolment, mobilization) has been critiqued as overly mechanistic (Fenwick and Edwards, 2010, p.14). The idea of discrete sequential stages detracts from a view of networks as fluid; it appears a simplification to suggest that a network has a distinct start and identifiable 'moments' of elaboration. I see networks as in constant circulation, at times coalescing into density, perhaps stabilising momentarily and then becoming diffuse and metamorphosing to reform elsewhere. The image I hold in mind is of a lava lamp. This infinite swarm of networks makes it difficult to limit the focus of study. Any boundaries of 'from here to here' are fundamentally arbitary. It is necessary to 'cut the network' (Fenwick and Edwards, 2010, p.15). In doing so, I find Callon's concepts of the 'obligatory passage point' and the moment of 'problematization' helpful. An obligatory passage point is one at which a particular framing of a problem is presented as incontrovertible. A particular problematization involves the selection of some entities for inclusion and others for exclusion. If entities are enrolled into the validity of the problematization they become engaged in identities and behaviours defined by the terms in which the problem is framed. Despite the critiques of Callon's model, and my own reservations about giving the appearance of linearity, I have found his concepts useful in my analysis and they will be referred to below.

Law $(1999$, p.10) reflects on the dangers of reductionism in attempting to render complexity. The analysis that follows is inevitably partial; describes some connections and ignores others, risks implying stasis where there may only be temporary stabilisation. However, I believe that an ANT sensibility may provide important insights into the contradictions of the Scottish context specifically and the process of appropriation generally. Researchers favouring an ANT sensibility are encouraged to 'follow the actors' (Latour, 2005, p.12). Starting with the assumption that the discourse of 'the social practice approach' is an actor-network, I first trace how it is an effect of the assemblage of other networks and then describe some processes of translation in which it is transformed to become equivalent to something else. As Hamilton, (2010, p.5) points out, this is not a simple process in which two different but predetermined entities become the same; rather the differences are smoothed, reconciled and 'held - precariously - in tension' by power relations. I concentrate on the role of two key actors in this process. Finally I consider the effects the discourse may have on the web of relations it is part of.

\section{'The social practice approach' as an effect of an assemblage of actor-networks}

The first trace of the 'social practice' discourse appears in the text of the Literacies in the Community: resources for practitioners and managers (LiC) pack (Adult Literacies in 
Scotland, 2000). This text was an artefact of the National Development Project - Adult Literacies in Scotland, established and funded by the Scottish Executive, managed by the City of Edinburgh Council Education Department, Community Education Group and involving a small group of experienced Scottish Adult Basic Education (ABE) practitioners. It was overseen by an Advisory Group which included representation from the Higher Education, Lifelong Learning, employment and enterprise sectors. Professor Mary Hamilton is listed amongst the members of this group. The 'recent research and theory' referred to on page 5 of the document is that of the NLS, in which Hamilton is a central figure. A variety of actors is then assembled in the production of this text. Practice networks (particularly those associated with community based adult learning and organised as Adult Basic Education services in Local Authorities) are connected with the actor of the NLS, itself a network of academics and discourses from different disciplines. Written by practitioners, for practitioners, the principles and examples of practice included in the pack are congruent with the definition of literacies as social practices asserted in the introduction. The format of the text, as a ring binder folder of 'resources', emphasises its connection to practice. The selfevaluation framework encourages practitioners to make connections between their own practice and the descriptions of 'good practice' provided in the pack.

In this assemblage, the actor-networks of practice and the NLS are most prominent. Those actors associated more overtly with work and the economy are less evident. The introduction, (written by the Director of Lifelong Learning Scottish Enterprise) asserts that 'Scotland's competitiveness in the global economy will require literate and numerate people who have the flexibility to cope with changing work practices' (p. v) but overall the text maintains a wider view of the purpose of literacies development. The connection to government agendas is through association with the text Communities Change through Learning, (Scottish Office, 1998), which evokes the vision of 'a democratic and socially just society' in its enrolment of actors into lifelong learning. The LiC pack maintains some distance from government; it is not obviously a government text but linked through its publication by Edinburgh City Council much more directly to practice.

This text might be described as an assemblage of actor-networks in which a translation of both practice and the NLS occurs in their new association. Ideas of good practice are changed by the association with NLS. The NLS, which theorises literacies in society, mutates into pedagogic principles as they are brought into relationship with community based ALN practice. A social practice perspective of literacies is made equivalent to a social practice approach to teaching and learning. The LiC pack may be seen as the first node in the actor- network of 'the social practice approach'. But it is not static. The pack is also an actor and, in the actor- network of ALN in Scotland, as we will see, it is allocated a role in which its relationships to practice and to the NLS are significantly changed. The LiC pack, in association with a discourse of performativity, agencies such as Her Majesty's Inspectorate of Education (HMIE) and funding criteria, becomes 'a cross-sectoral set of standards' for 'quality assurance' against 'performance indicators' (ALNIS, p.33). Its transformation, at another moment of translation, brings into new associations the entities it has gathered and transformed.

\section{ALNIS - the moment of problematization}

The National Development Project culminated in the text Adult Literacy and Numeracy in Scotland (ALNIS) (Scottish Executive, 2001). This report set out the Government's agenda 
in relation to ALN. Although ostensibly authored by the Adult Literacy Team of the National Development Project (a small group of 4 people - 2 HM Inspectors, a Director of Scottish Enterprise and the same practitioner who led on the production of the LiC pack) its voice claims wider authority and its association with government is overt. Clarke's (2002, p.115) metaphor of 'casting director' can be applied to the role of such a text. As both Clarke (2002) and Hamilton (2010) demonstrate in relation to the government ALN agenda in England, a government strategy document like this not only produces an assemblage of global and local networks, it enrols a variety of actors and assigns them specific roles. ALNIS, like Skills for Life in England, invokes the global actors of the OECD, international economic policy and the knowledge economy in its use of the IALS data as the basis of its problematization.

In Callon's (1986) framework of moments of translation, problematization is the stage at which a problem to be solved is defined on the terms of a key actor who is then able to identify other actors and claim to know what they want. ALNIS (Scottish Executive, 2001) defines the problem as 'the raising of adult literacy and numeracy levels' (p.2), the goal being 'to exceed the literacy and numeracy levels of Scotland's main competitors within the global economy' (p.18). As well as human actors - adults with low skills, ALN practitioners, Local Authorities, employers, a 'development engine' national agency - the report assigns roles to non-human actors, for instance the statistics of existing literacy levels, derived from IALS, ('around 800,000 adults in Scotland have very low literacy and numeracy skills' (p.7)), Community Learning Strategies, the LiC document, an ALN curriculum framework, professional qualifications, Individual Learning Plans and ICT.

Inconsistencies in the ways in which literacy is defined in this document have been noted by several commentators (Maclachlan and Cloonan, 2003; Ackland, 2006; Maclachlan, 2006). However, an alternative way of viewing the hybridity of discourse is to consider the text as an actor-network in which some actors are more powerful than others and translations occur in their association. The role of the OECD as a policy actor and its governance by international comparative studies has been written about extensively (Grek, 2009; Martens and Jakobi, 2010; Hamilton, 2012). The term 'social practices' never appears in the ALNIS text, though the definition of literacy and numeracy is the same as in the LiC pack and derived from the social practice perspective of NLS. NLS considers literacy to be 'more than skills' (Papen, 2005), however, the 'complex capabilities' referred to in LiC are reduced from skills, knowledge and understanding to merely skills in their association with the global networks and the IALS data, which invariably refer to literacy and numeracy 'skills'. The socio-cultural view of literacy of the NLS is further 'betrayed' in its translation in this text by an association with a deficit model in which adults in need of upskilling are to be identified by 'spotters and referrers' (p.18) and marshalled through the 'learning gateway' (p.25). The text as casting director assigns the role of raising the level of skills of these adults to practitioners in a wide range of agencies, through a partnership approach. It is significant that in reference to the principles of practice to be adopted, the text does not explicitly connect to NLS but instead to the knowledge of experienced practitioners, gathered through consultation with the field.

'For almost all of the respondents appropriate learning was equated with

- learner-centredness

- being aware of the learner's needs and circumstances

- using materials and delivery techniques appropriate to those needs.' (Scottish Executive, 2001, p.27) 
At this stage, the model of literacy education to be adopted is described as a 'lifelong learning approach' (p.14).

As casting director in this project, ALNIS claims to know what adults with low skills 'need', even those who are described as having 'latent' or 'invisible need' - i.e. those who do not themselves believe their skills to be inadequate. It also claims to know what practitioners need - national training, national standards, professional qualifications and professionalisation.

\section{Interessement and Enrolment}

In her analysis, Clarke groups these two moments of translation together. She demonstrates how the English Skills for Life strategy attempts to lock a range of actors into the relationships assigned by the problematization. The etymology of interessment implies that locking the actors into one set of relationships is to 'interpose' (Callon, 1986, p.8) between other alternative relationships:

'Where there may be competing definitions of actors' identities, barriers are constructed in an attempt to exclude actors outside the network who want to define them otherwise' (Clarke, 2002, p.117).

In ALNIS, the problematization attempts to lock practitioners into particular relationships to learners, to other agencies, to government. In terms of non-human entities, it attempts to define their relationships to Individual Learning Plans, the LiC pack, national standards, training, professionalisation, ICT. In particular, it seeks to interpose between practitioners and alternative forms of practice. According to Callon (1986, p.220) 'enrolment does not imply, nor does it exclude, pre-existing roles.' Indeed in this instance, practitioners may be more effectively enrolled to the problematization in ALNIS because the inscription of practice is derived from existing practice knowledge and experience. Connected to this in their new roles in the project, however, they are disconnected from the alternative forms of pedagogy proposed by the NLS.

At this obligatory passage point the social practice perspective connected to practice in the LiC pack becomes a spectre at the assembly of actors. A variety of barriers are interposed between practitioners and its alternative framing of the purposes of literacy and forms of literacy pedagogy.

\section{Mobilization}

In Callon's (1986) model, the moment of mobilization is the point at which the problem as defined, the actors and their relationships to one another are accepted as fact, become unquestionable. Following ALNIS, a number of the designated actors were effectively mobilised. The statistics of 'need' were quickly disconnected from their association with international agencies and ascribed instead to 'the Scottish Executive'; no longer identified as extrapolated figures, subject to criticism (ALNIS, p. 8), they are reported as fact: 'The former Scottish Executive found that 800,000 adults, of whom 500,000 were in work, had "significant literacy problems".'(Scotsman, Friday 4 December 2009). The 'shock statistics' (Maclachlan, 2006, p.200) are quickly put to work by practice managers to shift the direction of their agencies, legitimate their participation in local partnerships and to support the allocation of funding. 
'The resources were provided in response to the Adult Literacy and Numeracy in Scotland report 2000, which showed that $23 \%$ of adults were held back from full participation in Scottish life by their level of literacies skills' (Aberdeen City Council Adult Literacy and Numeracy in Aberdeen report, 2005)

'One in five workers in Scotland may struggle with literacy or numeracy tasks at work.' (WEA website).

How this fact has been assembled by the linkages of heterogeneous actor-networks becomes invisible and the fact is 'blackboxed' (Latour, 1987, p.13), simplified to something ready for use with its messy components helpfully packed out of sight.

Intermediaries such as funding, reporting and inspection mechanisms are used to discipline actors into the roles assigned. The significant funding directed to local literacy partnerships in Scotland required partnerships to provide and report on action plans, gather statistics and measure their progress towards goals determined in the ALNIS text. The format of reports constrained partnerships to report only on what was valued by the terms of the problematization:

'the framework does not allow the partnerships to describe the successes and developments in a way which is meaningful'

(Consultant's evaluation comments on partnership end year report 2004)

Other techniques of governance are more subtle. For example, professionalisation, one of the entities assembled in ALNIS, has the effect of mobilising practitioners through processes of normalisation and self regulation. 'Professional' becomes allied with accountable - i.e. adhering to the need to meet criteria relating to action planning, reporting and inspection. Such a pastoral form of governance 'enables individuals to actively participate in disciplinary regimes through investing their own identity, subjectivities and desires with those ascribed to them by certain knowledgeable discourses' (Usher and Edwards, 1998, p.215).

There are a number of reasons why practitioners in Scotland might have been attracted to the roles allocated them in ALNIS. For the first time in many years their work appeared to be needed, valued and resourced. Take-up of the roles allocated to them potentially brought the reward of professional status. The Cinderella service would go from rags to riches, if only she accepted the premise of the problematization and the performances prescribed. None of this, however, is very different from England or countless other contexts in which government policy with respect to adult literacy was framed in terms of the global discourses. In other contexts, however, the conditions of deployment chafed and the dissonance between policy and practitioner values generated concern. I believe the presence of the discourse of the 'social practice approach' has made the difference. To understand why, we need to consider the ground on which it has flourished.

\section{Power relations in local practice}

The Scottish strategy not only advocated partnership working but made it obligatory through its mechanism of distributing funding. The partnerships formed in each local authority area were, in my experience, uneasy alliances of agencies who had previously operated in distinct spheres of adult education, for example, Local Authority ABE services, FE colleges and voluntary sector adult education organisations such as the Workers' Education Association (WEA). The broader definition of 'literacies' allowed each to claim to have a role and thus access to much needed funding. Territorialism was rife, however, as ABE (which relied 
mainly on part time or voluntary unqualified staff) felt their terrain encroached upon and their expertise challenged by staff with higher status (colleges) or national co-ordination (WEA). As noted above, the depictions of good practice in ALNIS were attributed to experienced practitioners. ABE saw their own practice acknowledged in this and as good practice came to be further defined by national agencies as 'the social practice approach', believed that their expertise and territory could be shored up by reinforcing the link between the ALNIS depictions and the new terminology of pedagogy. They were thus invested in a claim to have always done 'social practices', unlike, in their view, the other agencies. The fusion of ALNIS (government strategy) with ideas of pedagogy served the interests of ABE in claiming the moral high ground. But the struggle for that ground was fierce, the voluntary sector, for instance, contesting it on the basis of their tradition of critical pedagogy, the colleges on the rigour of their institutional quality assurance processes. In this local conflict, ammunition was drawn from higher authorities at national level with little distinction between policy procedures and practice guidance. Hurled willy nilly into the uncomfortably unbounded space, statements from ALNIS seemed to collide with gestures from the LiC pack, with undigested gobbets of pedagogical theory.

Thus, within the partnerships, policy, pedagogy and practice appeared to be assembled as fortifications for each agency's position. The term social practices came to be used almost as a standard mark to promote agencies' provision as 'quality' practice. In this way practitioners across the range of provision became invested in the use of the concept; an investment which was further reinforced by the attention at international level for the Scottish 'experiment' (Merrifield, 2005). As the term 'social practice approach' became more fixedly associated with good practice, it was increasingly difficult for practitioners to question its meaning as to do so would carry the risk of relinquishing their claims to exemplary practice and the credit that flowed from this.

\section{Two ambivalent actors}

In the following years, 'the social practice approach' became a taken-for-granted thing, fused to assemblages that surrounded the ALN Initiative. To come closer to apprehending the power relations involved in the building of the social practice approach as an actor-network and, more significantly, its relationship to the actor-network of the ALN Initiative as established by ALNIS, I will explore the roles of two key actants in the mobilization: a national training course - The PDA:ITALL and 'the development engine' . I will suggest that in their different ways, these actants have been ambiguous and ambivalent. These ambiguities and ambivalences, far from threatening the facts established by ALNIS, may have contributed to the mobilization of a range of disparate practitioners and the performing into being 'the social practice approach'.

\section{The Professional Development Award: Introductory training in Adult Literacies Learning (PDA: ITALL)}

As the first national qualification, the PDA: ITALL played a crucial role in the professionalisation process and in the translation of the social practice approach. This Scottish Qualifications Agency (SQA) accredited training was developed to meet the ALNIS recommendations for a national training strategy (ALNIS, 2001, p.4). The course introduction claims it 'is built on the good practice guidelines and the seven guiding principles' of LiC and 'supports the unpacking of the theoretical ideas attributed to a Social Practice view of literacies.' IALS is referenced. A number of networks already in motion are 
hooked up in this statement - the LiC pack in its transformation from resources to standards, the social practice perspective on its way to becoming pedagogy, IALS statistics as they become facts.

Evolved from pre-existing local volunteer training and quickly adopted across Scotland as accreditation for all practitioners and a measure of local partnerships' accountability to government strategy, the course is a nexus of the range of entities of the network of ALN in Scotland. It connects, for example, local practice, practitioners and ALN partnerships with government strategy, the IALS data as rationalisation, the professionalisation agenda. The social practice discourse is also part of the assemblage:

'For tutors to be equipped with the necessary skills to engage confidently with adult learners in a learner centered, social practice context, it is vital that they be aware of, and begin to critically evaluate, current discourse in the field.' (SQA website).

Note how the term 'social practice' is co-located with the term 'leaner centred' which also appeared in ALNIS in relation to pedagogy.

Despite the assertion that the course aims to support critical practice within a social practices perspective of literacies, embedded within the learning outcomes is uncritical acceptance of assumptions on which the problematization of the ALNIS report is based. For example Unit 1 Outcome 1 requires candidates to: 'Explain why Scotland needs an adult literacies strategy and how the current strategy is being implemented'. The marking scheme lists elements that constitute an acceptable candidate response:

1. Research findings indicating the need for adult literacies provision: Name, date and findings of relevant reports, IALS, Project Papers, LiC with percentages of adults falling into relevant categories.

2. Policy priorities: ALNIS recommendations

The guidance for assessors directs them to expect in candidates' responses an uncritical reiteration of the problematization of ALNIS. The following quotation from an assessor, in which she describes how she supported a candidate to produce a successful response, illuminates the ways in which the course acts to bind practitioners to the framing of ALNIS:

'She just wasn't referring to the ALNIS report and the LiC pack in the way that the presenting centre wanted her to do...I had to say to her.... this is what they're really asking you to do - to look at the LiC pack and the ALNIS report, highlight some of these points and put them into your own words...say 'as per ALNIS report.." (ALN Training \& Development officer interviewed as part of CDA study, 2006).

In the identification of learning outcomes, marking schemes, exemplar responses and assessor moderation, the course acts to establish as 'facts' the assertions of ALNIS.

As the first and for a long time only qualification in ALN in Scotland, uptake was high as most partnerships insisted that even experienced practitioners achieve the accreditation. The demands were experienced as incontestable:

'we 've been told we have to do ITALL...we 've all been told... every one's been told you must have this qualification' (literacies tutor interviewed as part of research project, see Ackland, 2006)

However, it was not clear what authority such prescriptions emanated from; no government directive existed though reporting mechanisms did require some indications of partnerships' progress in improving the quality of practice. Although a low level qualification (SCQF 6 /EQF4) aimed at 'tutor assistants' and people new to ALN, the accreditation afforded by the 
PDA: ITALL became a tangible way of demonstrating quality in the service. In part, this became a way of evidencing compliance to the government strategy. For example, the 2005 newsletter of one partnership notes amongst its achievements: 'Increased number of literacies tutors trained to national standards'. Although no government directive existed to bind partnerships into this training, at local level there was a belief that it was a necessity: '.... when they brought in the national standard of ITALL, the idea was to create uniformity... if it's a national standard people have to engage with it.' (ALN Practice manager interviewed as part of research project, see Ackland, 2006)

Ten years on, almost no practitioner in Scotland has not been exposed to the PDA:ITALL, as a candidate, an assessor or a moderator. Notwithstanding the course aim that practitioners 'begin to critically evaluate current discourse in the field' , the effect of the course structure and processes is to blackbox the discourses of ALNIS and fuse these with the discourse of the social practice perspective. The course purports to 'support the unpacking of the theoretical ideas attributed to a Social Practice view of literacies' (ibid) but again the implications of this perspective for pedagogy are pre-determined by the assessment requirements rather than explored critically. What is stressed is the lifelong learning, learner- centred approach outlined in ALNIS, where it is attributed to the consensus of experienced practitioners rather than NLS.

To summarise: subject(ed) to the PDA:ITALL course practitioners are not just acculturated to their role in a social practice approach, but also mobilised to the ALNIS problematization. Far from being engaged critically with distinct discourses, practitioners are caught in the nexus of entities as these are translated 'into a single object or idea that can be mobilised and circulated like a ...taken for granted fact' (Clarke, 2002, p.114). The 'social practice approach' promoted by the course becomes collocated with the notion of learner-centredness, associated with the ALNIS project and translated - or betrayed - in the process. (A social practice approach is distinct from one that is merely learner-centred in that it challenges the inequities of power relations in literacy rather than merely supporting learners to function more effectively within these.) In the building of the actor-network of a social practice approach, the role of the course is ambiguous in advocating both criticality and adherence to discourses it acts to establish as facts. The overall effect is to build the actor-network of 'the social practice approach' as a single thing in which the disjunctions between different views of the purposes of literacies teaching are obscured.

\section{Learning Connections}

The ITALL course is a non-human actant. The 'development engine' assigned a role by ALNIS may also be considered a non-human entity as the agency Learning Connections. However, the agency is a collection of human individuals who have relationships with other individuals; in a small field of practice these are significant. As an agency, the role of Learning Connections has been ambiguous. With a focus on practice development, initially and more recently outside of government, it has at different times been assigned to policy implementation from within government and acted as an auditor of partnerships' progress towards targets. Described as 'implementing', 'rolling out', and 'overseeing' (e.g. Learning

1

http://www.understandingstandards.org.uk/markers ccc/mark main.jsp?pContentID=9024\&p applic=CCC\&p service=Content.show\&) 
Connections Report, Scottish Executive, 2005, p.4 and p.12) it is closely associated in the minds of practitioners with government and with ALNIS, in which it was designed.

It has had a crucial role in the building of the actor-network of 'the social practice approach'. Evolving out of the Scottish Literacies Project Development Team and including many of the same people, the early Learning Connections team had close links to the Lancaster School of NLS and took part in an Economic and Social Research Council series of seminars on the NLS (2002-2004). Those associations are clear in many of the practice-facing texts emanating from the team, starting with the LiC pack and particularly evident in the Curriculum Framework. As individuals, most members of the team came from practice and maintained links with practitioner groups in their role of practice development. They have initiated and led thematic practitioner networks (such as numeracy, prison literacies) and organised national seminars and training events. In all of these, the discourse of 'a social practice approach' was vocal.

The perception of Learning Connections from the field is of their power to determine both policy and practice.

'It is increasingly the perception that Learning Connections is reinventing the agenda nationally and imposing it on partnerships' (Local ALN partnership end year report, 2004).

Their vociferous assertion of 'the social practice approach' is experienced as a powerful directive linked to the ALNIS project by their role as policy implementers and overseers. The assemblage, as 'a single idea', becomes incontestable.

Hamilton and Hillier (2007, p.577) note the importance of 'deliberative spaces' for reflexive practice. In the decade of the Scottish ALN initiative such spaces have proliferated. Prior to 2001, connections between practitioners were few; the field was characterised by isolation, fragmentation and few opportunities for shared reflection. With the introduction of professional development, practitioners' networks, national seminars and an online 'community of practice' (COPAL) many more spaces for deliberation of practice have existed. However, almost all of these spaces were controlled by Learning Connections. Members of the team have chaired the networks, arranged the seminars, organised training events, moderated the online space (to which they are still the most prominent contributors). The effect has been to channel reflexivity in particular directions - to establish as doxa an official version of 'the social practice approach' - rather than to open spaces for practitioners to escape the tyranny of the ALNIS problematization of Adult Literacy.

\section{Conclusion}

'At the end of the process, if it is successful, only voices speaking in unison will be heard' (Callon 1986, p.223)

Talking about the uniformity exhibited in my data for the study of practitioners' constructions of 'the social practice approach', one tutor mused anxiously, 'Are we being churned out on a conveyor belt of ALN tutors?' The sense of being bound to an institutional ideology is expressed forcibly in the metaphor used in the words of another tutor:

'... in this day and age you'd get stoned to death if you're not doing the social practice model.' (Both quotes are from transcripts of data gathered as part of the research process, 2008.) 
It is paradoxical that a perspective which draws attention to the ideological basis of contested framings of literacies is translated in the actor-network of the Scottish 'social practice approach' into an uncritical technology applied to the ideological government project of skills for the economy. Whilst you might expect the social practice discourse to connect practice to the criticality of NLS and to afford a contestation of the ALNIS problematization and framing of literacy and education, instead by means of the ambivalent actor-networks described previously, it may have become the glue which has more safely bound practitioners to uncritical mobilization to the project.

The effect of professionalisation is to bind the interests of practitioners to government agendas and persuade them to perform their professionalism against the standards and targets set by the ALNIS problematization. As one measure of their professionalism, the accreditation process of the PDA:ITALL has the effect of fusing the social practice approach in practice with the 'needs' established in ALNIS through association with the IALS data. 'The social practice approach' becomes a blackbox in which the relationships between the heterogeneous entities of IALS, global economies, pre-existing principles of ALN practice, new theoretical understandings of literacies (NLS) are obscured to become taken for granted. As vociferous advocates of 'the social practice approach', ambivalent in their associations with both the government agenda and the NLS, the role of Learning Connections has been to authorise practice and deliver practitioners up more securely to the mobilization of the ALNIS project.

In ALIS 2020 (2010), the recent refresh of the ALNIS strategy, the role of the economy is strengthened with the discourse of employability. The project is more overtly to meet the needs of a competitive economy through meeting the needs of adults with low literacy skills. The social practice approach is promoted for its efficacy to this purpose. If 'the social practice approach' is not to be further translated in the powerful associations with employability, an intervention between the entities in the network must unpack the blackbox of 'the social practice approach'. Alternative deliberative spaces, not managed by central agencies, are needed wherein practitioners can construct their own understandings of what this approach might be in their own context and for the purposes of their learners. Within these spaces, it will be important to challenge the anti-theoretical culture of literacy practice, and to encourage practitioners to engage with research and theory. I believe there is a significant role for the universities in ensuring that theory and research are included in the assemblages of literacies education. With a critical pedagogy they can also use their role as teacher educators to examine the relationships between the entities assembled, interrupt associations and open up the possibilities for different combinations. The theory of literacies as social practices may be reconnected with Scottish 'the social practice approach'.

This has been a narrative constructed from some of the details of a particular case. Its purpose has been to illuminate a complex process of erasure in an apparently radical discourse. Whilst ANT rejects the notion of generalisablity, I hope it may tune readers' attention to similar transformations in their own context.

\section{References}

Ackland, A. (2006) 'Lizard Dressed as Lamb? A cautionary reading of the discourse of the Scottish adult literacies initiative', RaPAL, vol 60, pp. 37-45.

Ackland, A. (2010) 'Shifting the Discourse: Mediating Professional Identities in a Professional Development Community’, in B. Merrill and J. González Monteagudo (eds), 
Educational Journeys and Changing Lives. Adult Student Experiences, Seville: Edición Digital@3, vol 2, pp. 362-371.

Ackland, A. (2013) 'At play in the space: the concept of 'the social practice approach' in the Scottish Adult Literacies field', Literacy and Numeracy Studies: An international journal in the education and training of adults, vol 21(1), pp. 59-84.

Adult Literacies in Scotland (2000) Literacies in the Community, Edinburgh: City of Edinburgh Council.

Bernstein, B. (1981) 'Codes, modalities, and the process of cultural reproduction: A model', Language in Society, vol 10, pp. 327-363.

Burgess, A. (2008) 'The Literacy Practices of Recording Achievement: how a text mediates between the local and the global', Journal of Education Policy, vol 23(1), pp. 49-62.

Burgess, A. (2012) 'How Do Literacy Practitioners Exercise Agency as Policy Actors? A Study of the introduction of Functional Skills in England', RaPAL, vol 76, pp. 25-31. Callon, M. (1986) 'Some Elements of a Sociology of Translation: Domestication of the Scallops and the Fishermen of Saint Brieuc Bay' in J Law (ed), Power, Action and Belief: a new Sociology of Knowledge? Sociological Review Monograph, London: Routledge, pp. 196233.

Clarke, J. (2002) 'A new kind of symmetry?: Actor-network theories and the new literacy studies', Studies in the Education of Adults, vol 34(2), pp. 107-122.

Crowther, J., Hamilton, M. and Tett, L. (eds) (2001) Powerful Literacies, NIACE: Leicester. Crowther, J. and Martin, I. (2010) 'Adult education in Scotland: past and present', Concept vol 1(3).

Fairclough, N. (2003) Analysing Discourse, Oxon: Routledge.

Fenwick, T. (2011) 'Reading Educational Reform with Actor Network Theory: Fluid spaces, otherings, and ambivalences', Educational Philosophy and Theory, vol 43, pp. 114-134.

Fenwick, T. and Edwards, R. (2010) Actor-network theory in education, London: Routledge.

Fransella, F., and Bannister, D. (1977) A manual for repertory grid technique, London:

Academic Press Ltd

Goodson, I. (2003) Professional Knowledge, Professional Lives, Berkshire: Open University Press.

Hamilton, M. (2001) 'Privileged Literacies: Policy, Institutional process and the life of the IALS', Language and Education, vol 15(2), pp. 178-196.

Hamilton, M. (2009) 'Putting words in their mouths: the alignment of identities with system goals through the use of individual learning plans', British Educational Research Journal, vol 35(2), pp. 221-242.

Hamilton, M. (2011) 'Unruly Practices: What a sociology of translations can offer to educational policy analysis', Educational Philosophy and Theory, vol 43, pp. 55-75. Hamilton, M. (2012) 'The effects of the literacy policy environment on local sites of learning', Language and Education, vol 26(2), pp. 169-182.

Hamilton, M. and Hillier, Y. (2007) 'Deliberative policy Analysis: Adult literacy Assessment and the Politics of Change', Journal of Educational Policy, vol 22(5), pp. 573-594.

Hillier, Y. (2008) Evaluation of the Pilot Programme of the Teaching Qualification Adult Literacies, retrieved 6 June 2013 from

http://www.aloscotland.com/alo/viewresource.htm?id=272

Jones, J. and Macrae, C. (2008) Scoping Study on Models of Family Learning, Grangemouth: Linked Work and Training Trust.

Latour, B. (1987) Science in Action: How to Follow Scientists and Engineers Through

Society, Cambridge Mass., USA: Harvard University Press. 
Latour, B. (2005) Reassembling the Social-An Introduction to Actor-Network-Theory. reassembling the social, Oxford: Oxford University Press.

Law, J. (1999) 'After ANT: Topology, Naming and Complexity', in J Law and J Hassard (eds) Actor Network Theory and After, Oxford and Keele: Blackwell and the Sociological Review, pp. 1-14.

Maclachlan, K. (2006) 'Don't Look North Through Rose-tinted Spectacles: Tensions, struggles and guiding lights in Scotland - A reflection', RaPAL, vol 60, pp. 32-36.

Maclachlan, K. and Cloonan, M. (2003) 'Three Dimensional Change? The Relationship Between Theory, Policy and Adults' Understanding of Literacies', Research in PostCompulsory Education, vol 8(1), pp. 123-136.

Martens, K. and Jakobi, A. (eds) (2010) Mechanisms of OECD Governance International Incentives for National Policy-Making? Oxford: Oxford University Press.

Merrifield, J. (2005) 'Why England should look North for Inspiration', Reflect, vol 4, pp. 20 22.

Nespor, J. (2011) 'Devices and Educational Change', Educational Philosophy and Theory, vol 43, pp. 15-37.

National Development Project - Adult Literacies in Scotland (2000) Literacies in the community resources for practitioners and managers, Edinburgh, City of Edinburgh Council. The Organisation for Economic Co-operation and Development (OECD) website http://www.oecdbookshop.org/oecd/display.asp?lang=fr\&sf1=DI\&st1=5LMQCR2KBR45 [accessed 04/12/13]

Papen, U. (2005) Adult Literacy as Social Practice: More than skills, Routledge: London. Scottish Executive (2001) Adult Literacy and Numeracy in Scotland, Edinburgh: Scottish Executive.

Scottish Executive (2005) An Adult Literacy Curriculum Framework for Scotland, Edinburgh: Scottish Executive.

Scottish Executive (2005) Report on the Scottish Adult Literacy and Numeracy Strategy 2004-2005, Edinburgh: Scottish Executive.

Scottish Government (2011) Adult Literacies in Scotland 2020: Strategic guidance, Edinburgh: Scottish Government.

Singleton, V. and Michael, M. (1993) 'Actor-networks and Ambivalence: General Practitioners in the UK Cervical Screening Programme', Social Studies of Science vol 23, pp. 227-264.

Scottish Qualifications Authority website

http://www.understandingstandards.org.uk/markers_ccc/mark_main.jsp?pContentID $=9024 \&$ p_applic $=C C C \& p \_s e r v i c e=C o n t e n t$. show $\&$ [accessed 04/12/13]

Street, B. (1984) Literacy in Theory and Practice, Cambridge: Cambridge University Press. Swinney, A. (2013) Social Exclusion and Discourses of Literacy and Physical Activity (post16) in Scotland, PhD thesis, University of Edinburgh: U.K.

Tett, L. and Maclachlan, K. (2008) 'Learners, tutors and power in adult literacies research in Scotland', International Journal of Lifelong Education, vol 27(6), pp. 659-672.

Usher, R. and Edwards, R. (1998) Postmodernism and Education, London: Routledge.

Usher, R. and Edwards, R. (2007) Lifelong learning: Signs, discourses, practices, Dordrecht: Springer.

Workers Educational Association (WEA) website http://www.weascotland.org.uk/index.php?/NationalProgAdultLit [accessed 04/12/13] 
